\title{
Best practice in primary care pathology: review 8
}

\author{
W S A Smellie, K K Hampton, R Bowlees, S C Martin, N Shaw, J Hoffman, J P Ng, S M Mackenzie, \\ $C$ van Heyningen
}

J Clin Pathol 2007;60:740-748. doi: 10.1136/jcp.2006.044719

This eighth best practice review examines four series of common primary care questions in laboratory medicine: (i) sodium abnormalities; (ii) faecal occult blood testing; (iii) warfarin management; and (iv) sputum cytology in diagnosis of bronchopulmonary malignancy. The review is presented in question-answer format, referenced for each question series. The recommendations represent a précis of guidance found using a standardised literature search of national and international guidance notes, consensus statements, health policy documents and evidence-based medicine reviews, supplemented by Medline Embase searches to identify relevant primary research documents. They are not standards but form a guide to be set in the clinical context. Most are consensus rather than evidence-based. They will be updated periodically to take account of new information.

See end of article for authors' affiliations

.......

Correspondence to: Dr W S A Smellie, Department of Chemical Pathology, Bishop Auckland General Hospital, Cockton Hill Road, Bishop Auckland, County Durham DL14 6AD UK; info@smellie.com

Accepted 6 December 2006 Published Online First 15 December 2006

.....................

www.jclinpath.com
$\mathrm{T}$ his is the eighth in a planned series of reviews to answer a number of questions which arise in primary care use of pathology.

Each subject is introduced with a brief summary of the type of information found and is handled separately, with authorship attributed.

While the individual subjects are not related as they cover the disciplines of clinical biochemistry, microbiology, immunology, haematology and cellular pathology, they are designed, once comand cover a wide range of the most common primary care laboratory issues, to be made available to users.

Where the new UK General Medical Services (GMS) contracts make specific reference to a laboratory test, the indicator or target is appended at the end of the answer.

\section{HYPERNATRAEMIA AND HYPONATRAEMIA (CVH AND WSAS)}

Disorders of sodium and water balance are very common findings in primary care. The causes in most situations are readily identifiable from the clinical context, such as heart failure and/or diuretic use or dehydration. Frequently the patient's clinical state and the rate of change of the serum sodium are more important than absolute serum sodium values and the questions practitioners face often relate more to action levels rather than diagnosis. This review offers a guide to action limits when hyponatraemia has been identified and also outlines less common causes pleted, to form a resource which will be indexed of abnormal serum sodium concentration which are important to identify.

How should I investigate a patient with raised serum sodium concentration?

Hypernatraemia can be defined as a serum sodium $>145 \mathrm{mmol} / \mathrm{l}$.

We recommend:

- Repeat to confirm and establish whether acute and changing or chronic and stable. Changes of up to $5 \mathrm{mmol} / \mathrm{l}$ can reflect non-significant variation.

- Establish history of thirst, fluid intake and losses, and current treatments.

- Check for clinical features of dehydration and/ or hypovolaemia.

Depending on result:

- Persistent serum Na 146-148 mmol/l without clinical features of hypovolaemia may reflect a statistical population outlier.

- Serum Na 149-154 mmol/l

- Request serum potassium, urea, creatinine, calcium, and plasma glucose to evaluate further hydration status and renal function and exclude diabetes mellitus and hypercalcaemia as causes of dehydration

- Request serum lithium in lithium-treated patients

- Request urine and serum osmolality if diabetes insipidus suspected (in DI there is high serum osmolality ( $>300 \mathrm{mosm} / \mathrm{kg}$ ) and inappropriately dilute urine (less than serum))

- Consider specialist advice if clinical cause not apparent and oral rehydration, if indicated, is not realistically practical

- Serum $\mathrm{Na} \geqslant 155 \mathrm{mmol} / \mathrm{l}$

- Seek specialist advice or admission in addition to above

Hypernatraemia may be defined as a serum sodium concentration above the top of the population reference range $(145 \mathrm{mmol} / \mathrm{l})$. This range, however, reflects the $95 \%$ range within healthy populations. In addition to variations caused by imprecision of analysis, values outside the reference range will include $5 \%$ of a healthy population. Values of more than 3 standard deviations above the population mean ( $\geqslant 148 \mathrm{mmol} / \mathrm{l})$ will exclude many of the statistical anomalies and are more likely to be of clinical significance. 
The clinical context will in most cases indicate the cause (usually net water loss in mild to moderate hypernatraemia).

A repeat specimen to confirm the result is prudent to exclude sampling and laboratory errors. Differences in sequential serum sodium measurements of up to $5 \mathrm{mmol} / \mathrm{l}$ may reflect analytical and biological variation, highlighting the need to confirm results, although such factors rarely produce results significantly outside the reference range. Serum sodium can change rapidly, within days or weeks depending on the clinical context, so retesting intervals will depend on the suspected underlying pathology.

\section{Causes}

Hypernatraemia associated with hypovolaemia in primary care is caused by insufficient net intake of water or excessive net loss of water compared to sodium, through the skin, gut or kidneys. Depending on severity and rate of change of serum sodium concentration, hypernatraemia may be asymptomatic or produce the typical features of hypovolaemic hypernatraemia: dehydration, ranging from thirst and hypotension to confusion, somnolence and loss of consciousness. ${ }^{2}$ Hypernatraemia is rare in patients with a normal thirst response; when it does occur it is associated with a high mortality and high morbidity in survivors. ${ }^{1}$ Such patients tend to be at the extremes of age, such as infants in the first weeks of life or elderly institutionalised patients, who also may have thirst impairment and have less independent access to fluids (reviewed in Adrogué and Madias ${ }^{3}$ ). Newly presenting or decompensated diabetes mellitus should always be considered as a cause of hypernatraemia.

In a primary care context, hypernatraemia is unlikely to occur as a result of excessive sodium load due to iatrogenic or intentional high sodium intake; such cases would usually prompt secondary referral.

The patient's volume status should therefore be assessed and causes of hypovolaemia, if present, considered. ${ }^{1}$ The clinical history should identify water losses due to diarrhoea, vomiting, diuretics or failure to drink due to decreased thirst. Causes such as laxative or diuretic abuse may be more difficult to establish.

Head trauma, intracranial infection or stroke leading to cranial diabetes insipidus may arise in institutionalised elderly people. Nephrogenic diabetes insipidus may occur with advanced renal disease, hypercalcaemia or potassium depletion, or be secondary to drugs, including lithium or colchicine. ${ }^{14}$ Rare cases of congenital nephrogenic diabetes insipidus also occur. Serum and urine osmolality measurements will assist in identifying whether inappropriate urine dilution is occurring (high serum osmolality with inappropriately low urine osmolality occur in both cranial and nephrogenic diabetes insipidus). In the absence of clear guidance we would recommend that the results of these be discussed with the laboratory. Complex diagnostic algorithms have limitations in view of the many possible clinical scenarios in sodium imbalance; the clinical history and examination will reveal the cause in most cases.

While rare, excessive salt ingestion should be considered, particularly in situations of severe hypernatraemia, ${ }^{1}$ which would normally warrant urgent referral. Table 1 shows an overview of causes.

\section{Laboratory investigations}

In view of the above, recommended initial investigations include serum potassium, urea, and creatinine (most of which will usually be reported with the sodium result), serum calcium and lithium (in lithium-treated patients) and plasma glucose. If diabetes insipidus is suspected, random urine osmolality measurement will identify failure to concentrate urine and, if present, should guide rapid referral. Urine osmolality
$<150 \mathrm{mosmol} / \mathrm{kg}$ water in the presence of hypernatraemia and polyuria is cited as diagnostic of diabetes insipidus. ${ }^{4}$

\section{Treatment and referral}

Indications for referral will reflect a combination of clinical context, absolute sodium concentrations and rate of rise. No numerical thresholds were found. Hypernatraemia of $155 \mathrm{mmol} / \mathrm{l}$ may represent up to approximately 5-6\% net pure loss of body water in a dehydrated patient, although in the context of salt and water loss, the water loss may be greater; it appears reasonable to suggest that oral rehydration will become increasingly less practical as the value approaches $155 \mathrm{mmol} / \mathrm{l}$ in an otherwise healthy patient. If the hypernatraemia is $>155 \mathrm{mmol} / \mathrm{l}$, or if a cause other than dehydration is suspected, specialist advice is recommended. ${ }^{5}$ Clinical state rather than absolute sodium values is, however, more important.

Chronic hypernatraemia should be treated slowly and cautiously to prevent cerebral oedema. ${ }^{12}$

\section{How should I investigate a patient with low serum sodium concentration?}

We recommend:

- Establish history of fluid intake and current treatments.

- Assess fluid status, to identify whether hypovolaemia or hypervolaemia is present.

- Repeat to confirm and establish whether acute and changing or chronic and stable. Changes of up to $5 \mathrm{mmol} / \mathrm{l}$ can reflect non-significant variation.

Depending on result:

- Persistent and stable serum $\mathrm{Na}$ 132-135 mmol/l in a clinically well patient may reflect a statistical population outlier and may not require investigation unless there has been a large recent fall.

- Serum Na 125-131 mmol/l

- Check serum potassium, urea, creatinine, triglycerides, protein and plasma glucose

- If cause not clinically apparent, check urine $\mathrm{Na}$ and osmolality if syndrome of inappropriate antidiuretic hormone secretion (SIADH) suspected. Urine $\mathrm{Na}$ $>30 \mathrm{mmol} / \mathrm{l}$ and urine osmolality significantly higher than serum osmolality suggests SIADH

- Consider Addison's disease and hypothyroidism

- Consider reset osmostat syndrome in patients with chronic illness and stable hyponatraemia

- Consider artefactual causes: hyperproteinaemia (e.g. myeloma) and severe hyperlipidaemia

- Serum Na 115-124 mmol/l

- Check as above

- Seek specialist advice unless long-term stable and cause established

- Consider immediate admission if $\mathrm{Na}$ falling rapidly or neurological signs or symptoms present

- Serum Na $<115 \mathrm{mmol} / \mathrm{l}$

- Immediate admission usually indicated

Hyponatraemia may be defined as a serum sodium below the bottom of the population reference range $(135 \mathrm{mmol} / \mathrm{l})$. This range, however, reflects the $95 \%$ range within healthy populations. In addition to variations caused by imprecision of 
Table 1 Overview of the causes of hypernatraemia in primary care and guide to suggested action levels*

Hypernatraemia: causes

Net water loss

Diuretics

Vomiting and diarrhoea

Prolonged fever or sweating

Failure to drink/poor access to fluids

Diabetes mellitus

Hyperventilation

Nephrogenic diabetes insipidus

Cranial diabetes insipidus

Salt excess

Salt intoxication

*Thresholds for action and referral should, however, be based principally on clinical state and rate of change.

Hypernatraemia with a high/rising urea and only mild increase in creatinine is a useful adjunct to making a diagnosis of dehydration.

analysis, values outside the reference range will include $5 \%$ of a healthy population. Values more than 3 standard deviations below the population mean $(<132 \mathrm{mmol} / \mathrm{l})$ will exclude many of the statistical anomalies and are more likely to be of clinical significance.

Hyponatraemia can be described as mild (125-135 mmol/l), moderate $115-124(\mathrm{mmol} / \mathrm{l})$ and severe $(<125 \mathrm{mmol} / \mathrm{l}$ or $<115 \mathrm{mmol} / \mathrm{l}){ }^{6}{ }^{6}$ Hyponatraemia is a common finding in primary care, particularly in the elderly. It may be associated with hypovolaemia or hypervolaemia, and is caused more commonly by water retention than by insufficient net intake of sodium or excessive net loss of sodium compared to water through the skin, gut or kidneys. Depending on severity and rate of change of serum sodium concentration, hyponatraemia may be asymptomatic or produce symptoms extending to confusion, somnolence and loss of consciousness. ${ }^{1}$ Mild hyponatraemia $(125-135 \mathrm{mmol} / \mathrm{l})$ frequently does not cause symptoms. ${ }^{6}$ Symptoms of more severe hyponatraemia are related to degree and rate of decline ${ }^{5}{ }^{6}$; they may occur below $125 \mathrm{mmol} / \mathrm{l}$ and are usually present below $115 \mathrm{mmol} / \mathrm{l}^{6}$ and include nausea, malaise, headache, lethargy and disorientation. Slower onset, however, is more likely to present with fatigue or confusion. ${ }^{4} 6$

\section{Causes}

Many causes may be obvious from the clinical context. In practice, the commonest situations involve water retention, with or without salt retention, resulting in dilutional hyponatraemia (e.g. fluid retention in liver or heart disease), salt losing states with hypovolaemia (e.g. diuretic use), or euvolaemic hyponatraemia due to water retention caused by a range of drugs and conditions, grouped for ease under the term "syndrome of inappropriate antidiuretic hormone secretion" (SIADH) and analogous disorders. The history may also help to identify psychogenic polydipsia.

The patient's fluid volume status will provide a guide towards identifying causes which are not apparent. Table 2 shows some common causes of mild hyponatraemia seen in primary care. Water retention with whole body sodium excess is a more common mechanism than net salt loss. ${ }^{6}$

Extremely high serum triglyceride or protein concentrations may cause pseudohyponatraemia with normal serum osmolality. ${ }^{6}$ These conditions should therefore be excluded before diagnosing hyponatraemia.

The syndrome of inappropriate antidiuretic hormone secretion (SIADH), depending on cause (iatrogenic or malignancy), may represent a potential medical emergency, depending on rate of sodium fall. A similar mechanism is responsible for the hyponatraemia of some chronic illnesses (malignancy, malnutrition and debilitating illness) in which patients are euvolaemic and retain a normal concentrating response to fluid restriction. Here, serum sodium concentrations remain low but relatively stable (typically $125-130 \mathrm{mmol} / \mathrm{l}$ ).

Hypoadrenalism, although rare, is a potential medical emergency, and if suspected should prompt an urgent test of adrenal stimulation (short Synacthen test, in patients not receiving steroids) or immediate admission if acutely unwell. Specialist advice is recommended for suspected hypoadrenalism in patients who have been receiving systemic steroids.

\section{Laboratory investigations}

In view of the above, recommended initial investigations include serum potassium, urea, and creatinine (most of which will usually be reported with the sodium result).

Where the immediate cause is not clinically apparent, serum protein and triglycerides, and plasma glucose concentrations should be measured.

If no cause is identified from these investigations, serum osmolality to confirm a hypo-osmolar state and a random urine osmolality and sodium ${ }^{6}$ will guide towards renal sodium loss or inappropriate water retention and related disorders. Unlike hypovolaemic hyponatraemic patients, in whom the serum urea is usually raised and urine sodium $<20 \mathrm{mmol} / \mathrm{l}^{4}{ }^{6-9}$ in SIADH, the opposite is found: low serum urea and high urine sodium, usually $>30 \mathrm{mmol} / \mathrm{l},{ }^{5}$ combined with inappropriately concentrated urine compared to serum (typically $>100 \mathrm{mosmol} / \mathrm{kg}$ water in a hypo-osmolar patient ${ }^{4}{ }^{7}$ ).

If clinical features of Addison's disease are present (classically lethargy, nausea, weight loss, raised serum potassium and urea) a short Synacthen stimulation test is the recommended screening investigation rather than a random serum cortisol. Hypothyroidism must also be considered as a cause of hyponatraemia.

\section{Treatment and referral}

Acute symptomatic hyponatraemia and moderate or severe hyponatraemia $(<125 \mathrm{mmol} / \mathrm{l})$ should usually be managed in hospital or with specialist advice. ${ }^{58}$ In most cases the treatment is for the underlying cause. ${ }^{6}$ Heart failure with high dose diuretic treatment, for example, causes mild hyponatraemia which may be corrected with an ACE inhibitor. ${ }^{6}$ Apart from electrolyte replacement in severe diarrhoea or vomiting, sodium supplementation is very rarely indicated, as many of the patients in primary care will have salt and water retention due to their underlying disease. We would recommend this be done only with specialist advice.

Chronic mild hyponatraemia can often be managed at home. Treatment, depending on cause and other clinical needs, may be stopping or changing the drug responsible, if feasible, or correcting volume depletion if hypovolaemia is present.

While malignancy-related SIADH will usually prompt specialist referral, milder drug-induced cases may be managed by stopping or changing the drug implicated, and by fluid restriction to $500-750 \mathrm{ml}$ per day with specialist advice. ${ }^{46}$

GMS contract indicator: none

\section{FAECAL OCCULT BLOOD TESTING IN ADULTS WITH BOWEL SYMPTOMS (SMM AND SCM)}

Faecal occult bloods have long been contentious because of false positive and, particularly, false negative results and the implications of missing the potential diagnosis of malignancy. Cancer referral guidelines now place the emphasis on rapid secondary care investigation of suspected cancer patients, and the primary care use of investigations such as faecal occult blood testing is increasingly changing to endoscopic techniques. This question and answer set attempts to identify patients in 
Table 2 Overview of the causes of hyponatraemia in primary care and guide to suggested action levels*

Hyponatraemia: causes $^{58}$

Pseudohyponatraemia: hyperproteinaemia, hypertriglyceridaemia

Osmotic shift: hyperglycaemia

Hypovolaemia (with net sodium depletion)

Skin loss: sweating

Gut loss: vomiting, diarrhoea

Renal loss: diuretics, Addison's disease, hyperglycaemia

Hypervolaemia (with net water retention) Congestive cardiac failure

Cirrhosis with ascites

Nephrotic syndrome or chronic kidney disease

Clinical euvolaemia (due to water retention and sodium loss)

SIADH and related syndromes

Drugst

Malignancy; typically lung, upper gastrointestinal

Hypothyroidism

Chronic lung disease, infection, abscess

Cerebral injury, stroke, infection

*Thresholds for referral should, however, be based principally on clinical state and rate of change.

†Such as: antidepressants, e.g. tricyclics, selective serotonin reuptake inhibitors; antidiabetic drugs, e.g

chlorpropramide, metformin; antineoplastic agents, e.g. vinca alkaloids, cyclophosphamide, cisplatin; antipsychotic

drugs, e.g. phenothiazines, butyrophenones; analgesics, e.g. non-steroidal anti-inflammatory drugs; antiepileptic drugs,

e.g. carbamazepine, sodium valproate; diuretics, e.g. thiazides, amiloride; and other drugs, e.g. alpha interferon,

ecstasy.

whom this test may be appropriate in primary care and the means of obtaining the best results from the test.

\section{When should I do a faecal occult blood test in an adult with lower gastrointestinal symptoms?}

Patients under 60 years of age with change in bowel habit towards looser or more frequent stools $\geqslant 6$ weeks, without rectal bleeding, palpable abdominal mass, intestinal obstruction or iron deficiency anaemia.

Prodigy guidance, ${ }^{10}$ which follows that of NICE, ${ }^{11}$ cites the following criteria for urgent referral of suspected colorectal cancer and recommends that apart from a full blood count, abdominal and rectal examination, no other tests be performed, in order not to delay referral.

- Patients $\geqslant 40$ years old, with rectal bleeding and change of bowel habit towards looser and/or increased stool frequency lasting $\geqslant 6$ weeks.

- Patients $\geqslant 60$ years old, with rectal bleeding persisting for $\geqslant 6$ weeks without a change in bowel habit and without anal symptoms.

- Patients $\geqslant 60$ years old, without rectal bleeding with a change in bowel habit to looser and/or more frequent stools $\geqslant 6$ weeks.

- All patients presenting with a right lower abdominal mass consistent with involvement of the large bowel.

- Patients presenting with palpable rectal mass (intraluminal and not pelvic).

- All men with unexplained iron deficiency anaemia and haemoglobin $\leqslant 11 \mathrm{~g} / 100 \mathrm{ml}$.

- Non-menstruating women with unexplained iron deficiency anaemia and haemoglobin $\leqslant 10 \mathrm{~g} / 100 \mathrm{ml}$.

The Scottish SIGN guideline differs slightly, using a threshold of 50 years old and specifically adds intestinal obstruction as an indication for referral. ${ }^{12}$

- Rectal bleeding with a change in bowel habit to looseness or increased frequency.

- Rectal bleeding without anal symptoms.

- Palpable abdominal or rectal mass.

\section{- Intestinal obstruction.}

All patients with iron-deficiency anaemia $(\mathrm{Hb}<1 \mathrm{lg} / 100 \mathrm{ml}$ in men or $<10 \mathrm{~g} / 100 \mathrm{ml}$ in postmenopausal women) without overt cause should be thoroughly investigated for colorectal cancer.

It follows from this that only lower risk patients who would not require urgent referral should be considered for FOB testing, in order to expedite referral of positive cases, who are more likely to have bowel pathology.

\section{What faecal occult test type should I use and how many samples are required?}

We recommend:

- Guaiac based tests (such as Haemoccult) offer the best balance of specificity and sensitivity.

- Three samples should be collected over 3 days.. ${ }^{13}{ }^{14}$

Faecal occult blood testing (FOB) is a non-invasive, simple and rapid near patient test. Typical tests use a Guaiac impregnated paper, which produces a colour change in the presence of blood when a hydrogen peroxide developing solution is dropped onto the test.

A number of FOB kits are available, which vary in specificity and sensitivity. One study in 1990 compared three tests in symptomatic patients (Haemoccult, Fecatwin and E-Z Detect). ${ }^{15}$ These were used to test stool specimens from three sequential days. Using double contrast barium enema as a diagnostic test, the authors found Fecatwin to be the most sensitive. This test, however, gave three times as many false positive results as Haemoccult. The authors therefore concluded that a Haemoccult positive symptomatic patient had approximately a $50 \%$ probability of mucosal disease, and suggested this was the best of the three tests to use in the community, as long as the tester is aware that a negative result does not exclude serious pathology. E-Z detect is a patient interpreted test, where a sheet of benzidine impregnated paper is floated in the toilet in the presence of stool. This was less sensitive for blood than Haemoccult, and was not recommended in this study.

Other tests are available for patients to perform themselves, such as the Coloscreen Self-Test, a floating card the patient places in the toilet pan. However, when compared to the 
Haemoccult in symptomatic patients, while patient preference was greater for the self-test method, compliance was better with Haemoccult tests distributed for the patients to spot with faeces, again, over three consecutive days, and return to their practitioner. In this study, Coloscreen Self-Test was also less sensitive. ${ }^{16}$

Immunological tests also exist. One, Hemeselect, was compared with Haemoccult, in a population with gastrointestinal symptoms on three consecutive daily bowel motions. The immunological test was more sensitive but produced a higher false positive rate, with poorer specificity. The authors, however, concluded that due to the increased sensitivity for carcinoma, trials in asymptomatic patients may be justified. ${ }^{17}$

Faecal $\alpha_{1}$-antitrypsin assay has also been described as a marker of gastrointestinal bleeding. This quantitative test is slightly more specific than Haemoccult, but neither test was considered sensitive enough to justify routine use in high risk patients. ${ }^{18}$ Guaiac based testing appears to offer the best compromise between sensitivity and specificity, is most commonly used in the UK, and will be used in the planned asymptomatic screening programmes. ${ }^{19}$

\section{How do I interpret faecal occult blood test results in adult patients with lower gastrointestinal symptoms? We recommend:}

- Specific dietary advice should be given prior to obtaining specimens to minimise the false positive rate.

- Positive results indicate a significantly high likelihood of organic disease (although only about 30\% will have malignancy) and may guide urgency of referral.

- Negative results do not exclude organic pathology, and in symptomatic patients the test will only detect 2 out of 3 colonic cancers.

- Results must be therefore interpreted within the clinical context and risk setting.

The accuracy and value of Guaiac testing for symptomatic patients was investigated in 1983 using Haemoccult tests in a prospective study of 802 symptomatic patients referred from secondary care. The authors found a low false positive rate of $8.6 \%$, although the false negative rate was $45.4 \%$ when patients examined two samples from each of three consecutive stools. This could, they claim, be improved when combined with a "proper digital anorectal and proctosigmoidoscopic examination" to identify rectal tumours. ${ }^{20}$ There was, however, some debate about the interpretation of the data presented. ${ }^{21}$

A study of symptomatic referrals to secondary care in 1993, where 3 consecutive days' stools were tested, found $11 \%$ to be positive for occult blood using Haemoccult.

Of these, $63 \%$ were found to have colonic pathology. In comparison, fewer than $10 \%$ of those with a negative FOB test had significant findings when investigated. The authors concluded that although a positive FOB test was highly specific, a negative test did not "adequately exclude colonic pathology", and they suggest that the FOB test could be used as "guide to the urgency of investigation". 22

An older Australian study using Haemoccult tests on symptomatic patients also supported the belief that a positive FOB test can indicate higher likelihood, but not exclude, organic disease. ${ }^{23}$

Equally, a study published in 1995 by an Israeli group, studied symptomatic patients using Haemoccult FOB testing of two samples from each stool over 3 days and colonoscopy. For neoplastic lesions, sensitivity and specificity were both acceptable at $69.2 \%$ and $73.2 \%$; however the positive predictive value of the test was only $27.6 \%$. The patients in the trial undertook an appropriate exclusion diet before testing; however, the authors did emphasise the differences between the typical diet of their patients and the classical "Western" diet. The authors concluded that they could not recommend FOB testing in the investigation of the symptomatic patient. ${ }^{24}$ Overall, positive Haemoccult will detect around two-thirds of bowel cancers, and only approximately $25 \%$ of positive results will reflect malignancy.

Several factors, in addition to diet, ${ }^{25}$ are known to interfere with FOB testing. The American Cancer Society ${ }^{26}$ recommends avoiding non-steroidal anti-inflammatory drugs or aspirin (more than 1 adult aspirin per day) for 7 days before testing, or vitamin $\mathrm{C}>250 \mathrm{mg}$ daily (supplements or high fruit/juice intake) for 7 days before testing (false negatives); red meats for 3 days before testing (false positives); and raw broccoli, cauliflower, horseradish, parsnips, radishes, turnips and melons (vegetable peroxidases causing false positives) for 3 days before testing. However, it is emphasised that compliance is more important than strict dietary adherence.

Population screening is advocated by the American Cancer Society, National Cancer Institute and US Preventative Services Task Force in the US (summarised in State of New Jersey ${ }^{27}$ ), based on the large number (around 20\%) of asymptomatic cancers; over the next three years national screening programmes for colorectal cancer will be rolled out across the UK (http://www.cancerscreening.nhs.uk/bowel/_). These have been established following a successful pilot study in $2003 .{ }^{19}$ This will involve screening programmes targeting specific patients who are not necessarily symptomatic. Screening of asymptomatic populations will not be considered further in this answer.

\section{ANTICOAGULANT MONITORING (JPN, KKH)}

The great variation in response to warfarin between and within patients dictates the need to monitor and maintain the desired therapeutic international normalised ratio (INR) in order to ensure the effectiveness and safety of warfarin. It is also important to realise that careful selection and continuing risk assessment of patients with regard to hazards and benefits of anticoagulation is as important as INR monitoring.

Patient self-monitoring of anticoagulant therapy may be restrictive because of (i) exclusion rates $(>60 \%$, range $31-88 \%)$ based on trials evaluated, ${ }^{28}$ and (ii) the higher cost associated with self-monitoring, with one study ${ }^{29}$ quoting $£ 90$ (US\$175, $€ 130)$ as the cost for primary care monitoring compared to $£ 425$ (US\$835, €620) per patient/year for the self-monitoring group. The pressure on primary care to continue providing anticoagulant monitoring ${ }^{30}$ is therefore likely to continue.

\section{What INR monitoring is required for a patient on warfarin therapy?}

We recommend:

- Monitoring when initiating warfarin will depend on the initiation method

- Fennerty regimen for rapid anticoagulation (start with $10 \mathrm{mg}$ on first day, currently mostly in secondary care): INR daily for first 4 days at least, followed by weekly when INR value therapeutic and until INR stabilised

- A slow-loading regimen such as the Tait and Sefcick regimen (slower anticoagulation, $5 \mathrm{mg}$ daily for 4 days) is suitable for primary care): INR on days 5 and 8

- Individualised care or specialist advice is required for patients with baseline INR $>1.4$

- Monitoring when INR is stable

- Every 12 weeks, depending on historical stability and risk factors for destabilisation is recommended in the UK 
Table 3 Rapid induction regimen with warfarin

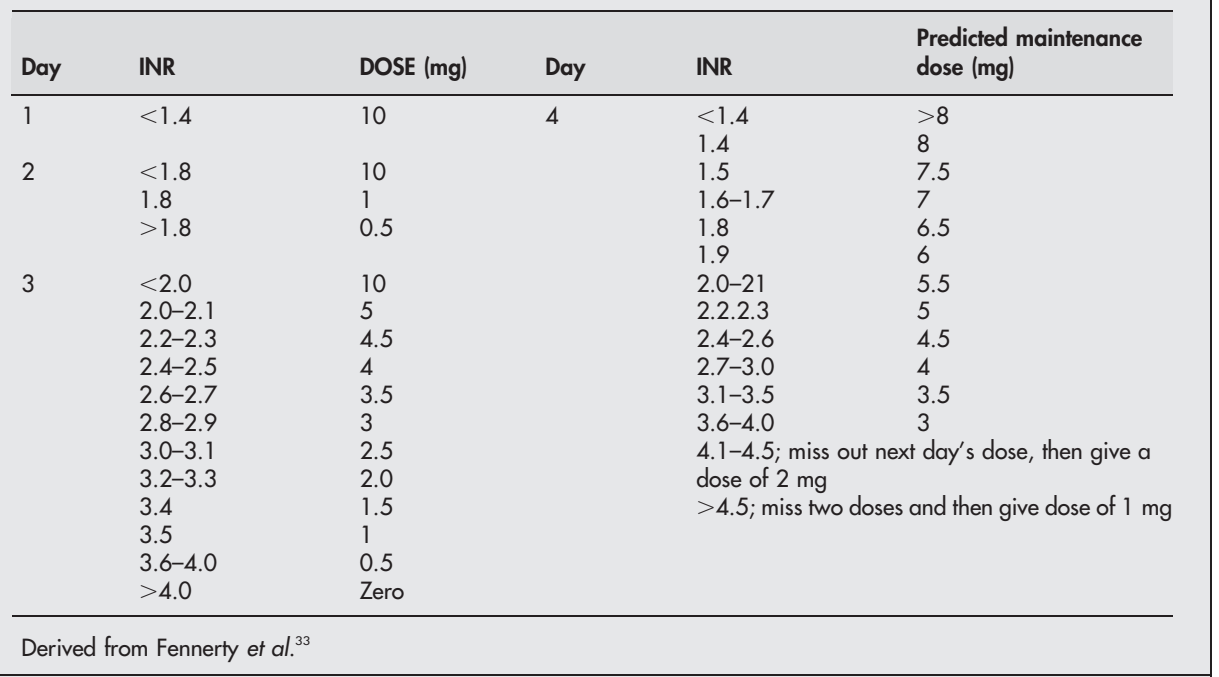

- Shorter periods are recommended elsewhere (4 weekly in US)

- Patient selection and continuing risk assessment are as important as INR monitoring.

The various indications for oral anticoagulation and their respective target INR are summarised in the third edition (2005) update of the British Committee for Standards in Haematology Guidelines (BCSH) on oral anticoagulation (warfarin). ${ }^{31}$ A recommendation for a target INR of 2.5 is made for most indications; the exceptions are a target INR of 3.0 for mechanical aortic valve prosthesis and 3.5 for mechanical mitral valve prosthesis and recurrence of venous thromboembolism while on warfarin therapy.

The efficacy and safety of warfarin is critically dependent on maintaining the INR in the therapeutic range. The aim of achieving target INR is to maximise reduction in thromboembolic risks while minimising the associated haemorrhagic risk. In patients who are at very high risk of bleeding, their optimal target INR may have to be lowered, sacrificing some efficacy for safety. ${ }^{32}$

Several regimens are available to guide clinicians in initiating and predicting maintenance dose of warfarin in individual patients. ${ }^{31}$ For patients who require rapid induction of oral anticoagulation (e.g. in acute venous thromboembolism when patients will also be on heparin), the most commonly used regimen is the Fennerty regimen ${ }^{33}$ (table 3 ), which recommends a starting warfarin dose of $10 \mathrm{mg}$ and daily INR monitoring during at least the first 4 days of treatment; after the desired therapeutic INR is achieved, weekly INR monitoring is recommended until the control is stable and the frequency of recall can then be extended. ${ }^{34}$ Other regimens are available for situations when heparin may not be required and when less rapid or more cautious induction of warfarin anticoagulation is considered appropriate or desirable (e.g. in chronic atrial fibrillation or elderly patients); such regimens are discussed in the BCSH guidelines on oral anticoagulation. ${ }^{31}$ One example is the Tait and Sefcick regimen, ${ }^{35}$ (table 4) which recommends an initial dose of $5 \mathrm{mg}$ warfarin for the first 4 days and INR check on day 5 and day 8 to predict subsequent warfarin dose. Both Fennerty and the Tait and Sefcick regimens rely on a normal baseline INR, defined as $<1.4$, at induction. The Tait and Sefcick regimen and the other slow-loading regimens ${ }^{31}$ are suitable for initiating warfarin anticoagulation in patients with atrial fibrillation in the community. As patients with acute thromboembolism are increasingly being managed in the community, primary care physicians may also become involved in the use of the Fennerty regimen.

Apart from a demonstrable stable dose response to warfarin, the frequency of long-term INR monitoring depends on individual patient characteristics, which include drug compliance, change in drug history and other co-morbid conditions.

Table 4 Slow induction regimen with warfarin

\begin{tabular}{|c|c|c|c|}
\hline Day 5 INR & $\begin{array}{l}\text { Dose } \\
\text { (for days 5-7) }\end{array}$ & Day 8 INR & Dose (from day 8) \\
\hline$\leqslant 1.7$ & $5 \mathrm{mg}$ & $\begin{array}{l}\leqslant 1.7 \\
1.8-2.4 \\
2.5-3.0 \\
>3.0\end{array}$ & $\begin{array}{l}6 \mathrm{mg} \\
5 \mathrm{mg} \\
4 \mathrm{mg} \\
3 \mathrm{mg} \text { for } 4 \text { days }\end{array}$ \\
\hline $1.8-2.2$ & $4 \mathrm{mg}$ & $\begin{array}{l}\leqslant 1.7 \\
1.8-3.4 \\
2.5-3.0 \\
3.1-3.5 \\
>3.5\end{array}$ & $\begin{array}{l}5 \mathrm{mg} \\
4 \mathrm{mg} \\
3.5 \mathrm{mg} \\
3 \mathrm{mg} \text { for } 4 \text { days } \\
2.5 \mathrm{mg} \text { for } 4 \text { days }\end{array}$ \\
\hline $2.3-2.7$ & $3 \mathrm{mg}$ & $\begin{array}{l}\leqslant 1.7 \\
1.8-2.4 \\
2.5-3.0 \\
3.1-3.5 \\
>3.5\end{array}$ & $\begin{array}{l}4 \mathrm{mg} \\
3.5 \mathrm{mg} \\
3 \mathrm{mg} \\
2.5 \mathrm{mg} \text { for } 4 \text { days } \\
2 \mathrm{mg} \text { for } 4 \text { days }\end{array}$ \\
\hline $2.8-3.2$ & $2 \mathrm{mg}$ & $\begin{array}{l}\leqslant 1.7 \\
1.8-2.4 \\
2.5-3.0 \\
3.1-3.5 \\
>3.5\end{array}$ & $\begin{array}{l}3 \mathrm{mg} \\
2.5 \mathrm{mg} \\
2 \mathrm{mg} \\
1.5 \mathrm{mg} \text { for } 4 \text { days } \\
1 \mathrm{mg} \text { for } 4 \text { days }\end{array}$ \\
\hline $3.3-3.7$ & $1 \mathrm{mg}$ & $\begin{array}{l}\leqslant 1.7 \\
1.8-2.4 \\
2.5-3.0 \\
3.1-3.5 \\
>3.5\end{array}$ & $\begin{array}{l}2 \mathrm{mg} \\
1.5 \mathrm{mg} \\
1 \mathrm{mg} \\
0.5 \mathrm{mg} \text { for } 4 \text { days } \\
\text { omit for } 4 \text { days }\end{array}$ \\
\hline$>3.7$ & $0 \mathrm{mg}$ & $\begin{array}{l}<2.0 \\
2.0-2.9 \\
3.0-3.5\end{array}$ & $\begin{array}{l}1.5 \mathrm{mg} \text { for } 4 \text { days } \\
1 \mathrm{mg} \text { for } 4 \text { days } \\
0.5 \mathrm{mg} \text { for } 4 \text { days }\end{array}$ \\
\hline
\end{tabular}

Derived from Tait and Sefcick. ${ }^{35}$ The regimen relies on a baseline INR $<1.4$, warfarin dose $5 \mathrm{mg}$ daily for first 4 days, INR result on day 5 predicting the warfarin dose on day 5-7, and INR result on day 8 predicting the warfarin dose on day 8 and beyond.

At day 15 (or day 12), check INR and make fine dose adjustment as appropriate. 
While the recommended frequency of INR monitoring for stably controlled patients in North America is no less than every 4 weeks, ${ }^{32}$ intervals of up to 12 weeks is accepted or recommended practice ${ }^{3436}$ in the UK; longer intervals of at least 14 weeks have even been suggested. ${ }^{39}$

While anticoagulant monitoring should be managed by trained personnel, computer-assisted dosage adjustment can also help to achieve better INR control. ${ }^{32}{ }^{40}$ To help with dosing, Baglin ${ }^{41}$ refers to a simple algorithm for calculating a new dose of warfarin based on the degree of over-anticoagulation; he also provides a validated simple dose reduction scheme for management of over-anticoagulation (table 5). The BCSH guidelines ${ }^{31} 34$ provide details on management of bleeding and excessive anticoagulation with warfarin; hospital admission will be required for some groups of patients.

\section{What additional monitoring is required if a patient starts a drug which can interfere with warfarin? \\ We recommend:}

- Consider all prescribed and non-prescribed drugs (notably herbal products and vitamin $\mathrm{K}_{1}$-containing multivitamins) as being potentially able to interfere with warfarin.

- Drugs with less risk of interference within a therapeutic class should be preferred.

- Short term treatment $(<5$ days) may not require monitoring, although omission or reduction of one dose may be considered for drugs known to interfere.

- Longer term treatment should prompt INR check one week after starting (or stopping) and subsequent monitoring as dictated by the result.

Management of warfarin drug interactions is complicated by either lack of good quality information regarding drug interactions ${ }^{42}{ }^{43}$ or significant post-marketing drug interactions being reported in spite of negative pre-marketing drug interaction studies. ${ }^{42}$ However, the number of reports of interactions between warfarin and drugs or foods is increasing, which reflects widespread use of anticoagulant therapy and its use with concomitant medications ${ }^{43}$ A similar challenge applies with herbal products. ${ }^{42}$ Self medication with over-the-counter vitamin $\mathrm{K}_{1}$-containing multivitamins is also problematic. ${ }^{44} \mathrm{~A}$ regular and detailed history of pharmacological and nonpharmacological medications from patients on warfarin is therefore always essential.

It is wise to assume that almost any drug can interact with oral anticoagulants. ${ }^{34}$ When prescribing new medication for patients on warfarin, clinicians are strongly advised to refer to

Table 5 Simple dose reduction scheme for management of over-anticoagulation

\begin{tabular}{lll}
\hline INR & \% dose reduction & $\begin{array}{l}\text { Number (days) of } \\
\text { omitted doses }\end{array}$ \\
\hline $\begin{array}{ll}\text { Target INR 2.5 } \\
3.0-3.5\end{array}$ & 15 & 0 \\
$3.6-4.0$ & 20 & 0 \\
$4.1-5.0$ & 25 & 0 \\
$5.1-6.0$ & 25 & 0 \\
$6.1-7.9$ & 33 & 2 \\
$>8.0$ & 50 & 3 \\
Target INR 3.5 & & \\
$4.1-5.0$ & 15 & 0 \\
$5.1-6.0$ & 20 & 0 \\
$6.1-7.9$ & 33 & 2 \\
$>8.0$ & 50 & 3 \\
\hline
\end{tabular}

Derived from Baglin. ${ }^{4}$ appropriate sources of information on drug interactions, such as the British National Formulary, ${ }^{36}$ available on-line (http:// www.bnf.org/bnf/), which list the drugs with known predictive pharmacological interactions with warfarin resulting in over- or under-anticoagulation; if such drugs cannot be avoided, more frequent INR monitoring will be required and the dose of warfarin adjusted as necessary. On-line resources for herbal product drug interactions are also available from the National Institutes of Health (Office of Dietary Supplements; http:// dietary-supplements.info.nih.gov/) $)^{37}$ and National Center for Complementary and Alternative Medicine (http://nccam.nih. gov)..$^{38}$ Moreover, while accepting some limitations, it would appear sensible to choose a drug that is least likely to interact with warfarin, based on knowledge of drug metabolism or negative result in drug interaction studies. For example, citalopram has the lowest general risk of interaction with warfarin among the selective serotonin reuptake inhibitors, ${ }^{41}$ and rabeprazole would be preferred over omeprazole in choosing a proton pump inhibitor. ${ }^{43}$

The decision as to when to check the INR when a new drug is prescribed depends on the duration of therapy and if the drug is known to interact with warfarin. For short courses of new drug therapy, dose adjustment of warfarin is not necessary, although a slight dose reduction or omission of one dose could be considered if a known potentiator is prescribed. ${ }^{34}$ If the new drug is prescribed for more than 5 days, the INR should be checked 1 week after starting and the dose of warfarin adjusted accordingly. ${ }^{34}$ Likewise, monitoring to a new maintenance dose of warfarin may be required when a drug is discontinued.

\section{SPUTUM CYTOLOGY (WSAS AND JH)}

Cancer referral guidelines now place the emphasis on rapid secondary care investigation of suspected cancer patients; the primary care use of investigations such as sputum cytology (in the context of suspected malignancy) is increasingly changing to higher performing imaging and endoscopic techniques. This question-answer set attempts to identify situations in which primary care requesting of sputum cytology may be appropriate

\section{When should I request sputum cytology?}

We recommend:

- Sputum cytology should not be used for population screening.

- A chest $x$ ray is the most appropriate primary care investigation for suspected lung cancer. Criteria can be found at http:// www.prodigy.nhs.uk/guidance.asp?gt = Lung\%20cancer\%20$\% 20$ suspected.

- Sputum cytology is not usually indicated prior to secondary care referral.

- When performed on secondary care recommendation, 3-5 early morning specimens should be sent, either for immediate delivery or preserved according to local recommendations.

The United States Preventative Services task force has found evidence that while lung cancer screening using a variety of techniques, including sputum cytology, can detect lung cancer at an earlier stage than without screening, it found poor evidence for a screening policy reducing mortality. ${ }^{45}$

The sensitivity of sputum alone has been reported to be 10 $20 \%,{ }^{46}$ and $42 \%$ in one series, ${ }^{47}$ although many series have reported detection rates of $60 \%$ to up to $90-95 \%$ from sequential 5 day series of sputa with 5 day collections ${ }^{48}{ }^{49}$; one study cited poor specimen conditions as a reason to explain this. There appears good consensus that correctly obtained and processed samples are important to maintain sensitivity. When collected, a minimum standard of $3,^{50}$ or ideally $3-5^{51}$ early morning 
specimens are recommended, ${ }^{5253}$ taken from symptomatic patients with productive cough, and submitted either immediately to the laboratory or preserved in accordance with local recommendations.

Mass sputum screening is also not recommended by the American Society of Cytopathology, ${ }^{53}$ American Cancer Society and US National Cancer Institute (reviewed in Office of Cancer Control and Prevention ${ }^{54}$ and considered to be inefficient ${ }^{55}$ ).

In patients suspected of suffering from lung cancer, the American College of Chest Physicians Guideline, ${ }^{56}$ containing contributions from 13 American and international medical associations, recommended that the diagnosis be obtained by "whichever method is the easiest...as dictated by the patient's presentation", from sputum cytology, fine needle aspiration and bronchoscopic methods of obtaining specimens. While it states that sputum cytology in a centre with a formal programme for using this in the diagnostic workup is a reasonable first step, it states that it is of limited sensitivity; negative results do not exclude the diagnosis and require further investigation.

Prodigy guidance, ${ }^{57}$ based on the UK Department of Health Referral Guidelines, ${ }^{58}$ recommends that sputum cytology be rarely indicated prior to specialist referral, but that a chest $x$ ray is an appropriate primary care investigation. This guidance includes criteria for requesting a chest $x$ ray and for urgent specialist referral. A 2-week standard also exists in the UK for patients with suspected lung cancer to be seen by a specialist. ${ }^{59}$ In view of this and the above guidelines, it would appear appropriate in the specific UK context, to refer suspected cases immediately and either leave the decision on the means of obtaining a cytological diagnosis to the specialist centre or discuss with the centre before performing.

GMS contract indicator: none.

\section{CONCLUSION}

This eighth review brings to a running total of 94 questionanswer sets written in order to provide an overview of current advice in use of laboratory tests in primary care. Answers to the first seven question-answer sets can be found elsewhere. ${ }^{60-66}$ They have all used a common search methodology, ${ }^{67}$ although where recent systematic reviews have been performed, the guidance relies heavily on the findings of these reviews. For authors wishing to consult the UK General Medical Services Contract and related Quality and Outcomes Framework, these can be found on their respective websites. ${ }^{68-70}$

\section{ACKNOWLEDGEMENTS}

We thank Mrs Susan Richardson for typing this manuscript, Mrs GC Smellie for help in collating answers into this article and the following people who kindly reviewed the work: Dr P Gosling (Association of Clinical Biochemists), Prof. R Gama, Dr MJ Galloway (Association of Clinical Pathologists), Dr N Campbell (Royal College of General Practitioners), Dr E Logan (Royal College of Pathologists), and the other council members of these associations and colleges who have assisted in recruiting reviewers.

\section{Authors' affiliations}

W S A Smellie, Department of Chemical Pathology, Bishop Auckland General Hospital, Bishop Auckland, UK

K K Hampton, Department of Haematology, Royal Hallamshire Hospital, Sheffield, UK

R Bowlees, N Shaw, Sowerby Centre for Health Informatics, All Saints Business Centre, Newcastle upon Tyne, UK

S C Martin, Department of Clinical Biochemistry, West Suffolk Hospital, Bury St Edmonds, UK

J Hoffman, Department of Histopathology, Bishop Auckland General Hospital, Bishop Auckland, UK

J P Ng, Department of Haematology, Barnsley Hospital NHS Foundation Trust, Barnsley, UK
S M Mackenzie, Department of Clinical Biochemistry, Royal Infirmary of Edinburgh, Edinburgh, UK

C van Heyningen, Department of Clinical Biochemistry, University Hospital Aintree, Liverpool, UK

Funding: This work has been supported (in alphabetical order) by the Association of Clinical Biochemists*, Association of Clinical Pathologists*, Association of Medical Microbiologists, British Society for Haematology, Royal College of General Practitioners, Royal College of Pathologists* and the Sowerby Centre for Health Informatics in Newcastle (SCHIN), representatives of whom have contributed to the reviewing process. The opinions stated are however those of the authors. ${ }^{*}$ These organisations contributed direct funding to support the project start up.

Competing interests: None declared.

\section{REFERENCES}

1 eMedicine. Hypernatraemia. www.emedicine.com/emerg/topic263.htm (accessed 10 Aug 2006).

2 EBM. Hypernatraemia. www.ebm-guidelines.com.

3 Adrogué HJ, Madias NE. Hypernatremia. N Engl J Med, 342:1493-9.

4 Kugler JP, Hustead T. Hyponatraemia and hypernatraemia in the elderly. Am Fam Physician 2000;61:3623-30.

5 Reynolds RM, Padfield PL, Seckl JR. Disorders of sodium balance. BM 2006;332:702-5.

6 EBM. Hyponatraemia. www.ebm-guidelines.com.

7 Milionis HJ, Liamis GL, Elisat MS. The hyponatraemic patient: a systematic approach to laboratory diagnosis. CMAJ 2002;166:1056-62.

8 eMedicine. Hyponatraemia. October 2005 update. www.emedicine.com/ emerg/topic275.htm (accessed 10 Aug 2006).

9 Oh MS. Pathogenesis and diagnosis of hyponatraemia. Nephron. 2002;92: 2-8, Prodigy.www.prodigy.nhs.uk, (Suppl 1).

10 Prodigy. Guidance on suspected lower gastro-intestinal cancer. http:// www.prodigy.nhs.uk/gi_lower_cancer_suspected/view_whole_guidance (accessed 30 Oct 2006)

11 NICE. Clinical guideline 27. Referral for suspected cancer, 2005.http:// www.nice.org.uk/page.aspx?o $=c g 027$ niceguideline (accessed 2 Oct 2006)

12 SIGN. Management of colorectal cancer. SIGN, 2003. http://www.sign.ac.uk/ pdf/sign67.pdf (accessed 2 Oct 2006).

13 Thomas WM, Pye G, Hardcastle JD, et al. Faecal occult blood screening for colorectal neoplasia: a randomized trial of three days or six days of tests. $\mathrm{Br} J$ Surg 1990;77:277-9.

14 Greegor DH. Occult blood testing for detection of asymptomatic colon cancer. Cancer 1971;28:131-4

15 Tate JJ, Northway J, Royle GT, et al. Faecal occult blood testing in symptomatic patients: comparison of three tests. Br J Surg 1990;77:523-6.

16 Pye G, Jackson J, Thomas WM, et al. Comparison of Coloscreen Self-Test and Haemoccult faecal occult blood tests in the detection of colorectal cancer in symptomatic patients. Br J Surg 1990;77:630-1

17 Thomas WM, Hardcastle JD, Jackson J, et al. Chemical and immunological testing for faecal occult blood: a comparison of two tests in symptomatic patients. Br J Cancer 1992;65:618-20.

18 Moran A, Husband D, Jones AF, et al. Diagnostic value of a Guaiac occult blood test and faecal alpha 1-antitrypsin. Gut 1995;36:87-9.

19 UKCCSPG. Results of the first round of a demonstration pilot of screening for colorectal cancer in the United Kingdom. BMJ 2004;329:133.

20 Leicester RJ, Lightfoot A, Millar J, et al. Accuracy and value of the Haemoccult test in symptomatic patients. Br Med J (Clin Res Ed) 1983;286:673-4.

21 von Krogh H, Siem H. Letter. BMJ 1983;287:216.

22 Falkson CB, Bates T. Faecal occult blood screening for patients with gastrointestinal symptoms. Br J Surg 1993;80:1326.

23 Goulston K, Davidson P. Faecal occult blood testing in patients with colonic symptoms. Med J Aust 1980;2:667-8.

24 Niv Y, Sperber AD. Sensitivity, specificity, and predictive value of fecal occult blood testing (Hemoccult II) for colorectal neoplasia in symptomatic patients: a prospective study with total colonoscopy. Am J Gastroenterol 1995;90:1974-7.

25 Thomas WM, Pye G, Hardcastle JD, et al. Role of dietary restriction in Haemoccult screening for colorectal cancer. Br J Surg 1989;76:976-8.

26 Cancer Society. http://www.cancer.org/docroot/CRl/content/ CRI_2_6X_Colorectal_Cancer_Early_Detection_10.asp (accessed 30 Oct 2006).

27 State of New Jersey. Department of Health and Senior Sciences. Guideline Comparison. www.state.nj.us/health/ccp/guidelines.htm /accessed 30 Oct 2006).

28 Heneghan C, Alonso-Coello P, Garcia-Alamino JM, et al. Self-monitoring of oral anticoagulation: a systematic review and meta-analysis. Lancet 2006;367:404-11.

29 Fitzmaurice DA, Murray ET, Gee KM, et al. A randomised controlled trial of patient self management of oral anticoagulation treatment compared with primary care management. J Clin Pathol 2002:55:845-9.

30 Fitzmaurice DA, Hobbs FDR, Murray ET, et al. Oral anticoagulation management in primary care with the use of computerised decision support and near-patient testing: a randomised, controlled trial. Arch Intern Med 2000;160:2343-8.

31 Baglin TP, Keeling DM, Watson HG. Guidelines on oral anticoagulation (warfarin): third edition-2005 update. Br J Haematol 2005;132:277-85. 
32 Ansell J, Hirsh J, Poller L, et al. The pharmacology and measurement of the vitamin K antagonists: the Seventh ACCP Conference on Antithrombotic and Thrombolytic Therapy. Chest 2004;126:204-33.

33 Fennerty $A$, Dolben J, Thomas $P$, et al. Flexible induction dose regimen for warfarin and prediction of maintenance dose. BMJ 1984;288:1268-70.

34 Guidelines on oral anticoagulation: third edition. $\mathrm{Br} J$ Haematol 1998;101:374-87.

35 Tait RC, Sefcick A. A warfarin induction regimen for out-patient anticoagulation in patients with atrial fibrillation. Br J Haematol 1998;101:450-4.

36 British National Formulary 51. March 2006. http://www.bnf.org/bnf/ (accessed 30 Oct 2006).

37 National Institutes of Health (Office of Dietary Supplements). http://dietarysupplements.info.nih.gov/ (accessed 30 Oct 2006).

38 National Center for Complementary and Alternative Medicine. http:// nccam.nih.gov (accessed 30 Oct 2006)

39 Lidstone V, Janes S, Stross P. INR: intervals of measurement can safely extend to 14 weeks. Clin Lab Haem 2000;22:291-3.

40 Poller L, Schaich CR, MacCallum PK, et al. On behalf of the European Concerted Action on Anticoagulation. Lancet 1998;352:1505-9.

41 Baglin T. Management of warfarin (coumarin) overdose. Blood Rev 1998;12:91-8.

42 Wittowsky AK. Drug interactions update: drugs, herbs, and oral anticoagulation. J Thromb Thrombolysis 2001;12:67-71.

43 Holbrook AM, Pereira JA, Labris R, et al. Systematic overview of warfarin and its drug and food interactions. Arch Intern Med 2005;165:1095-106.

44 Kurnik D, Loebstein R, Rabinovitz $\mathrm{H}$, et al. Over-the-counter vitamin $\mathrm{K}_{1}$ containing multivitamin supplements disrupt warfarin anticoagulation in vitamin $\mathrm{K}_{1}$-depleted patients. Thromb Haemost 2004;92:1018-24.

45 US Preventative Services Task Force. Screening for lung cancer. http:// odphp.osophs.dhhs.gov/pubs/guidecps/text/CH1 1 .txt (accessed 26 May 2006)

46 Marfin AA, Schenker MB. Screening for lung cancer: effective tests awaiting effective treatment. In: Harber P, Balmes JR, eds. Occupational medicine state of the art review:prevention of pulmonary disease. Philadelphia: Hanley \& Belfus, 1991:111-31.

47 The National Cancer Institute Cooperative Early Lung Cancer Detection Program. Summary and conclusions. Am Rev Respir Dis 1984;130:565-7.

48 Erozen YS, Frost JK. Cytopathologic diagnosis of lung cancer. Semin Oncol 1974:1:191-8

49 Koss LG, Melamed LR, Goodner JT. Pulmonary cytology, a brief survey of diagnostic results from July 1st 1952 until December 31 st 1960. Acta Cyto 1964;8:104-13.

50 Bocking A, Biesterfield S, Chatelain R, et al. Diagnosis of bronchial carcinoma on sections of paraffin-embedded sputum. Sensitivity and specificity of an alteration to routine cytology. Acta Cytol 1992;36:37-47.
51 Johnston WW Bossen EH. Ten years of respiratory cytopathology at Duke University Medical Center. I. The cytopathologic diagnosis of lung cancer during the years 1970 to 1974, noting the significance of specimen number and type. Acta Cytol 1981;25:103-7.

52 DeMay RM. Respiratory cytology. In:The art and science of cytopathology. Chicago: ASCP Press, 1996

53 American Society of Cytopathology. Non-gynecology practice guideline. http://www.cytopathology.org/website/article.asp?id = 17 (accessed 26 May 2006)

54 Office of Cancer Control and Prevention. Guideline comparisons. http:// www.state.nj.us/health/ccp/guidelines.htm (accessed 26 May 2006).

55 Wright JL, Coppin C, Mullen BJ, et al. Surgical treatment of lung cancer: promise and problems of early diagnosis. Can J Surg 1986;29:205-8.

56 Rivera MP, Detterbeck F, Mehta AC. Diagnosis of lung cancer: the guidelines. Chest 2003;123(1 Suppl):129S-36S

57 Prodigy. Guidance. Lung cancer-suspected. http://www.prodigy.nhs.uk/ guidance.asp?gt = Lung\%20cancer\%20-\%20suspected (accessed 26 May 2006)

58 Department of Health. Referral guidelines for suspected cancer. http:// www.dh.gov.uk/assetRoot/04/01/44/21/04014421.pdf (accessed 26 May 2006)

59 White Paper. The new NHS - modern dependable. http://www.archive.officialdocuments.co.uk/document/doh/newnhs/newnhs.htm /accessed 26 May 2006).

60 Smellie WSA, Wilson D, McNulty CAM, et al. Best practice in primary care pathology: review 1. J Clin Pathol 2005;58:1016-27.

61 Smellie WSA, Forth J, McNulty CAM, et al. Best practice in primary car pathology: review 2. J Clin Pathol 2006;59:113-20.

62 Smellie WSA, Forth J, Bareford, et al. Best practice in primary care pathology: review 3. J Clin Pathol 2006:59:781-9.

63 Smellie WSA, Forth J, Sundar S, et al. Best practice in primary care pathology: review 4. J Clin Pathol 2006;59:893-902.

64 Smellie WSA, Forth J, Ryder S, et al. Best practice in primary care pathology: review 5. J Clin Pathol 2006;59:1229-37.

65 Smellie WSA, Forth J, Coleman JJ, et al. Best practice in primary care pathology: review 6. J Clin Pathol 2007;60:225-34.

66 Smellie WSA, Forth J, Smart SRS, et al. Best practice in primary care pathology: review 7. J Clin Pathol 2007:60:458-65.

67 Smellie WSA, Wilson D, Finnigan DI, et al. Best practice in pathology. methodology for constructing guidance. J Clin Pathol 2005;58:249-53.

68 General Medical Services Contract. www.nhsconfed.org/docs/contract.pdf (accessed 3 Oct 2005).

69 NHS Confederation. Quality and outcomes framework. Accompanying guidance document. 2003. NHS Confederation. www.nhsconfed.org/docs/ quality_and_outcomes_framework_guidance.pdf (accessed 3 Oct 2005)

70 NHS. Revisions to the GMS contract 2006/7. http://www.nhsemployers.org/ primary/index.cfm (accessed 3 March 2006). 


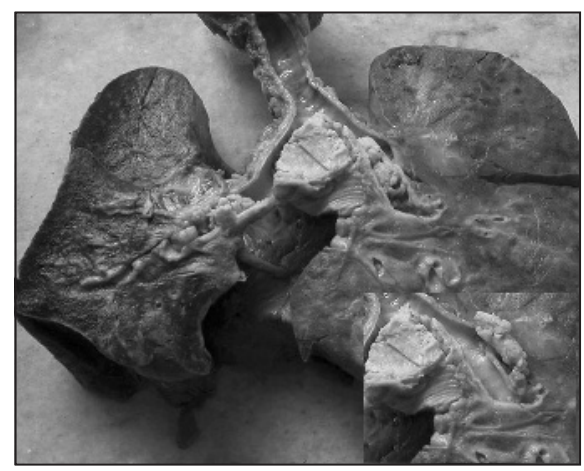

Figure 1 Sessile polypoidal friable carinal tumour with tumourous occlusion of both the main bronchi. Note collapsed left lung and hyperinflated right lung. Inset: smooth right bronchial mucosa after scooping out the tumour fragment.

was sudden respiratory distress and the child died.

Autopsy revealed a $2 \times 1.8 \times 1.7 \mathrm{~cm}$, sessile, polypoidal, soft, whitish-yellow exceedingly friable tumour in the carina and left main bronchus (fig 1). The left lung was collapsed, firm with a dark brown cut surface. An unattached friable piece of tumour $(0.9 \times 0.4 \mathrm{~cm})$ was present in the lumen of the right main bronchus. Removal of the right bronchial luminal fragment revealed smooth and glistening underlying mucosa (fig 1, inset). The right lung was voluminous, oedematous and haemorrhagic. On histology, a benign spindle cell tumour, arranged in intersecting fascicles, was seen to originate from the carinal smooth muscles (fig 2). The cells were stained red by Masson trichrome stain, with a strong immunoreactivity for smooth muscle actin, and were non-reactive to EBV antigen (EBNA) and CDl17. No tumour was seen elsewhere.

Predisposing factors for bronchopulmonary leiomyomata in adults have not been well documented. In sharp contrast, in children, immunodeficient states have served as fertile grounds for benign and malignant smooth muscle proliferations. ${ }^{2}$ Chadwick et $a l^{3}$ first described pulmonary leiomyoma in three HIVpositive children; prior to their report, only eight children with such tumours had been reported. ${ }^{3}$ Since then, 18 cases have been described with HIV infection and other immunodeficient states. $^{24}$ Ours will be the 19th patient. The role of EBV in smooth muscle tumourigenesis in immunocompromised conditions has been proved beyond doubt. ${ }^{2}$ In the reported case, the HIV status was not available. There were no features suggesting primary or acquired immunodeficiency. Immunohistochemistry was negative for EBV antigens. In an attempt to delineate the histogenesis, we used an immunostain for CD117, as the tracheo-bronchial tree is a foregut derivative. However, this was nonreactive. Benign endobronchial or parenchymal leiomyomata have always been described as "firm" or "hard". Surprisingly, this tumour

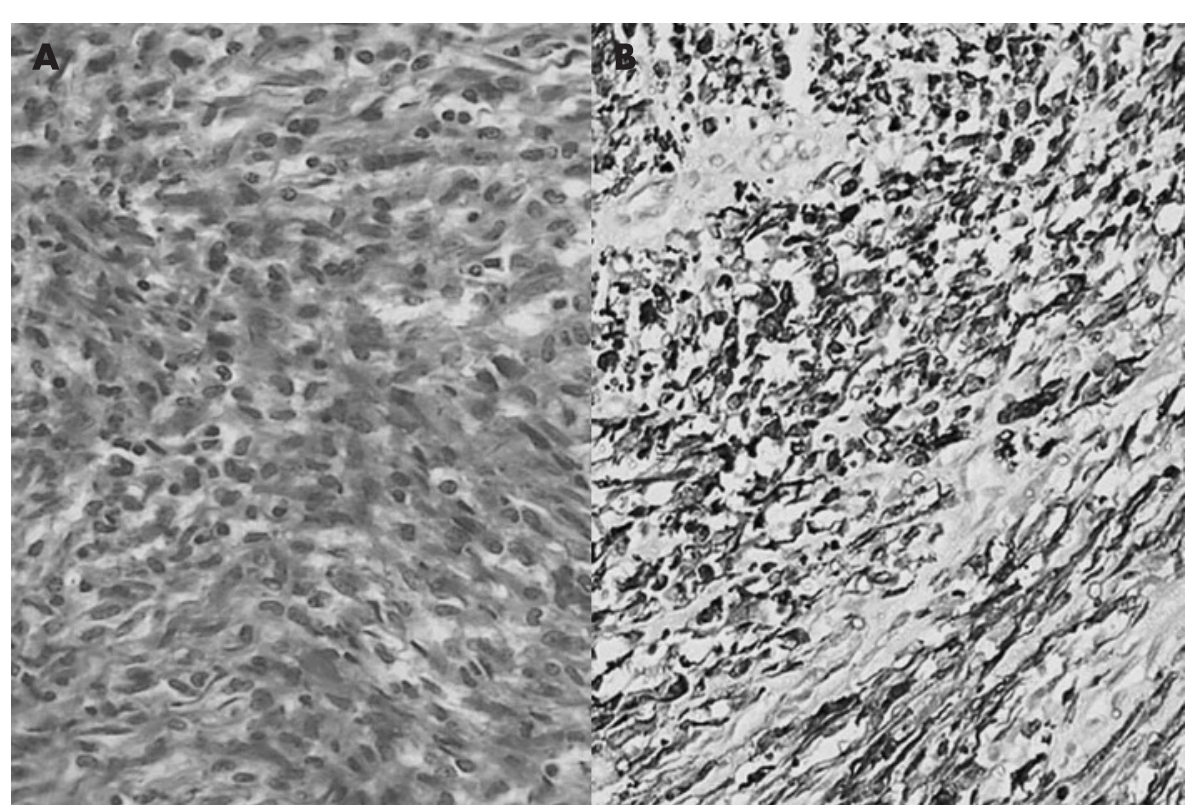

Figure 2 (A) Interlacing bundles of spindle-shaped cells without pleomorphism or mitoses (H\&E, $\times 400)$. (B) Strong positivity with smooth muscle actin $(\times 400)$. was extremely friable. A fragment had broken off from the main mass to occlude the right bronchus, which precipitated the fatal respiratory distress. Such a phenomenon, though not previously reported, should be borne in mind when diagnostic bronchoscopy is attempted. The tumours are amenable to surgical or endoscopic intervention. It is important to assess the HIV and EBV status when tumours are multifocal or involve extra-pulmonary sites.

\section{Ruta Goregaonkar}

Department of Pathology, Tata Memorial Hospital, Mumbai, India

Pradeep Vaideeswar, Shobhana P Pandit Department of Pathology (Cardiovascular \& Thoracic Division), Seth G S Medical College, Mumbai, India

Correspondence to: Dr Pradeep Vaideeswar, Department of Pathology (Cardiovascular \& Thoracic Division), Seth G S Medical College, Parel, Mumbai 400 012, India; shreeprajai@yahoo.co.in

\section{doi: $10.1136 /$ icp.2006.046136}

Accepted 4 January 2007

Competing interests: None declared.

\section{References}

1 Sekine I, Kodama I, Yokose T, et al. Rare pulmonary tumors - a review of 32 cases. Oncology 1998; $55: 431-4$

2 Hatano $M$, Takada $H$, Nomura A, et al. EpsteinBarr virus-associated bronchial leiomyoma in a boy with cellular immunodeficiency. Pediatr Pulmonol 2006;41:371-3.

3 Chadwick EG, Connor EJ, Hanson CG, et al. Tumors of smooth-muscle origin in HIV-infected children. JAMA 1990;263:3182-4.

4 de Chadarevian JP, Wolk JH, Inniss S, et al. A newly recognized cause of wheezing: AIDS-related bronchial leiomyomas. Pediatr Pulmonol 1997;24:106-10.

\section{CORRECTIONS}

doi: 10.1136/jcp.2006.044719.corrl

There was an error in an author name in the July issue of the journal (Smellie WSA, Hampton KK, Bowlees R, et al. Best practice in primary care pathology: review 8 . $J$ Clin Pathol 2007;60:740-8.) The correct name of the third author is R Bowley.

doi: 10.1136/jcp.2006.041251.corr l

There was an omission in an article published in the August issue of the journal (Lee DH, Lee GK, Kong S-Y, et al. Epidermal growth factor receptor status in anaplastic thyroid carcinoma. J Clin Pathol 2007;60:881-4.) The following statement should have been included: DHL and GKL contributed equally to this work. 